\title{
Towards a Cybernetic Theory and Reference Model of Self-designing Complex Collaborative Networks
}

\author{
Hadi Kandjani and Peter Bernus \\ Centre for Enterprise Architecture Research and Management (CEARM) \\ School of ICT, Griffith University, Brisbane, Australia \\ \{H.Kandjani, P. Bernus\}@griffith.edu.au
}

\begin{abstract}
The multi-disciplinary and inter-disciplinary movement studying Collaborative Networks (CNs) introduced terminologies, reference architectures, methodologies and models, with the aim of helping the design, creation, operation and maintenance of CNs, and its virtual organisations (VOs). Almost a decade ago, the IST European VOMap project reported a lack of 'well founded theory and models' for sustainable collaborative networks, and this article is an attempt into this direction. The article defines and introduces 'Cybernetics of Collaborative Networks' (C2N) as a field of $\mathrm{CN}$-research intended as a unified theory of $\mathrm{CNs}$, formalising, synthesising, harmonising and systematising individual $\mathrm{CN}$-related results addressing management and control problems in CNs. Through this envisaged synthesis, the paper invokes a number of relevant reference models and corresponding theories to outline a possible reference model and theory for self-designing CNs.
\end{abstract}

Keywords: Collaborative Networks, Cybernetics, Enterprise Reference Architecture and Methodology, Self-designing systems, Self-evolving systems.

\section{Introduction}

For the study of Collaborative Networks, like for any other developing discipline, there is a need for a roadmap $[1,2,3,4,5,6,7,8]$ attempting to facilitate the integration of previous results into a theoretical foundation (including terminology, axioms, models, methodologies). The study of complex CNs requires a theory that allows the analysis and modeling of properties such as complexity, emergence, self-organization, dynamics, etc. E.g., while the study of emergence started a rapidly developing trend in CNs, the new types of CNs, and ways of collaboration are not well understood yet. Camarinha-Matos and Afsarmanesh (2008a) argue that the required theoretical foundation must consolidate the existing body of knowledge, and provide grounding to define how to invoke results of other relevant disciplines.

There can be various theories of CNs, depending on what relevant questions we intend to answer. Almost a decade ago, the IST European VOMap project reported [1] a lack of 'well founded theory and models' for sustainable collaborative networks, and this article is an attempt into this direction. The theory of which a possible initial formulation is presented here is intended to explain the structure of processes (and thereby create 
predictive models) of how collaborative activity creates controllable, sustainable and evolving enterprise networks (and their 'offspring' VEs / VOs).

Cybernetics, Management Cybernetics and General Systems Theory (GST) have already previously attacked the problem of designing, creating and managing and sustaining complex systems $[9,10,11]$. Cybernetic thinking provides a method to unify (and relate) the apport of multiple disciplines: it can be used to represent the essence of multiple theories using abstract functions and processes, meta-processes, and their relationships, and governing axioms (likely to be expressed using a suitable logic).

A relevant field of study called 'Enterprise Architecture Cybernetics (EAC)' $[12,13]$ has a similar purpose and level of abstraction to this intended theory, however EAC has a different scope and genericity (namely its scope encompasses all sociotechnical systems of systems in the broadest sense, including social, economic and ecological systems, and aggregates thereof). In order to formulate a specific enough (and practically usable) theory, Cybernetics of CNs (C2N) could follow EAC, but elaborate it with $\mathrm{CN}$-specific detail, and illustrate the theory with relevant examples. For the purpose of theory development we need to harmonise the terminology of a number of relevant reference models and corresponding sub-theories - see Section 4.

Norbert Wiener defined cybernetics as "the science of control and communication in the animal and machine" [14]. According to Ashby [9] "truths of cybernetics are not conditional on their being derived from some other branch of science", therefore the field embraces a set of self-contained groundings and foundations, which he tried to describe in his book [9]. Ashby proposed that the study of the complexity of systems is one of the peculiarities of cybernetics. Stafford Beer [10] believed that the dynamics of enterprises is "the manipulation of men, material, machinery and money" and the "management of complexity". He coined the term 'management cybernetics' and believed that over the last two centuries, the whole of science has been based on reductionism however cybernetics uses a holistic paradigm [15].

Using this holistic paradigm for $\mathrm{CNs}$ and VOs, they can be thought of as intrinsically complex adaptive living systems instead of 'designed systems': deliberate design processes are mixed with emergent change. This mix may create a situation where CNs/VOs maintain (for some stretch of time) a dynamic equilibrium a property studied in General Systems Theory [11,16]. As the evolution of the CNs includes emergent as well as the deliberate aspects of change, and we believe that the CNs discipline needs to interpret previous research in both.

\section{Design Concerns in CN-Design and Evolution}

Introducing a theoretical foundation for $\mathrm{CNs}$ requires two directions [7]: 1) Consolidation (structuring of the body of existing empirical knowledge), and 2) Adoption (extension of theories and modeling tools developed elsewhere, to understand and explore emerging forms of collaborative networks/ their behavioral patterns), but also the study of new forms of CNs as complex systems needs the contribution of several disciplines (computer science/engineering, management, economy, sociology, industrial engineering, law). EAC [12] as a new field of EA research has the same level of abstraction and purpose: to 
invoke relevant disciplines when studying enterprises as complex systems. Kandjani and Bernus argued and demonstrated in case studies that to study and explore CNs and VOs as complex systems, researchers not only apply models, methods and theories of management and control, but those of engineering, linguistics, cognitive science, environmental science, biology, social science, law, AI, systems thinking and cybernetics $[12,13]$. Using EAC, they demonstrated the application of Axiomatic Design and Complexity theory to measure, calculate and reduce the structural complexity of $\mathrm{CNs}$ $[12,17]$.

A unified theory of CNs and VOs must take into account the list of concerns different disciplines that studied the design and evolution of complex systems. A way to express these concerns [13] is through metaphors, i.e. 'design' or 'architecture' as:

- Conversation Process between the system's operations, the system's controller, and the environment (using Conversation Theory [18],

- Decisional Process in the management and control system [19, 20],

- Design Process as viewed by Axiomatic Design Theory [21],

- an Emergent and Evolutionary Process in Complex Adaptive Systems [22,23],

- Planning \& Prediction process shaped by negotiation among designer agents (using theories of Multi-Agent Systems and other AI theories [24,25]),

- Participatory Process, using Participatory Design Approach [26],

- Learning Process, using Systems thinking and Cybernetics theories [9,27,28].

To ensure that the unified theory has sufficient breadth and depth, not only is this review useful to understand underlying concerns, it could extend the $\mathrm{CN}$ Body of Knowledge. Cybernetics formulated laws and theories of complex systems, but presented them on various levels of formality, generality and abstraction, so their application in the $\mathrm{CN}$ discipline lacks harmony: there is a need for a 'Cybernetics of CNs' (C2N) a field on its own (a special case of EAC) to (using systems thinking and cybernetics) select, harmonise, formalise, synthesise, and systematise previous results applicable to the field. $\mathrm{C} 2 \mathrm{~N}$ is to re-interpret old and new theories, and point at the need for new results for designing / creating complex CNs. Cybernetic thinking is able to provide a method of unifying (and relating) the apport of multiple disciplines, and the synthesis could be the source of a new, unified reference model for CNs.

\section{Cybernetics of Collaborative Networks (C2N) as an Evolving Discipline}

The CNs discipline, like any other developing discipline, needs a model for theory development/ testing/ knowledge creation [7]. Anderton and Checkland [29,30] developed a model of developing disciplines to demonstrate the cyclic interaction between theory development, problem formulation, and theory testing. For $\mathrm{C} 2 \mathrm{~N}$ (Fig.1) we consider the real world $\mathrm{CN}$ problem domains as the source of the discipline development process a source of issues to be addressed by the theory, its models / methods, and by related disciplines. The issues shape ideas to develop two types of theories [30] a) substantive theories derived from related disciplines applying them in 
the $\mathrm{CN}$ domain, and b) methodological theories (about how to invoke CN/VO related disciplines in the $\mathrm{CN}$ domain). Once we have such theories, we can state problems not only existing problems in the concrete $\mathrm{CN}$ domain, but also more abstract problems within the new theory. Finally, such a new theory of CNs may be used to develop an interdisciplinary methodology to be used in CNs practice.

Results of the synthesis must be used in practice to create 'case records', to provide the source of criticism to improve the theory being formulated (and as a result, the models, techniques, and methodologies). This should be documented in case records to provide feedback to improve the individual- and the unified theories.

This article is only treating a first step, the enumeration of theories that address issues arising from network complexity. The second step would be to clarify the issues addressed, terminologies used, and the set of axioms (for theories that are formalised). The third step would be to map the above against a common model of management and control processes. The common model could serve as a 'terminological grounding' and could be the basis of a reference model accompanying a unified theory (in a way staking out the domain of the theory's applicability).

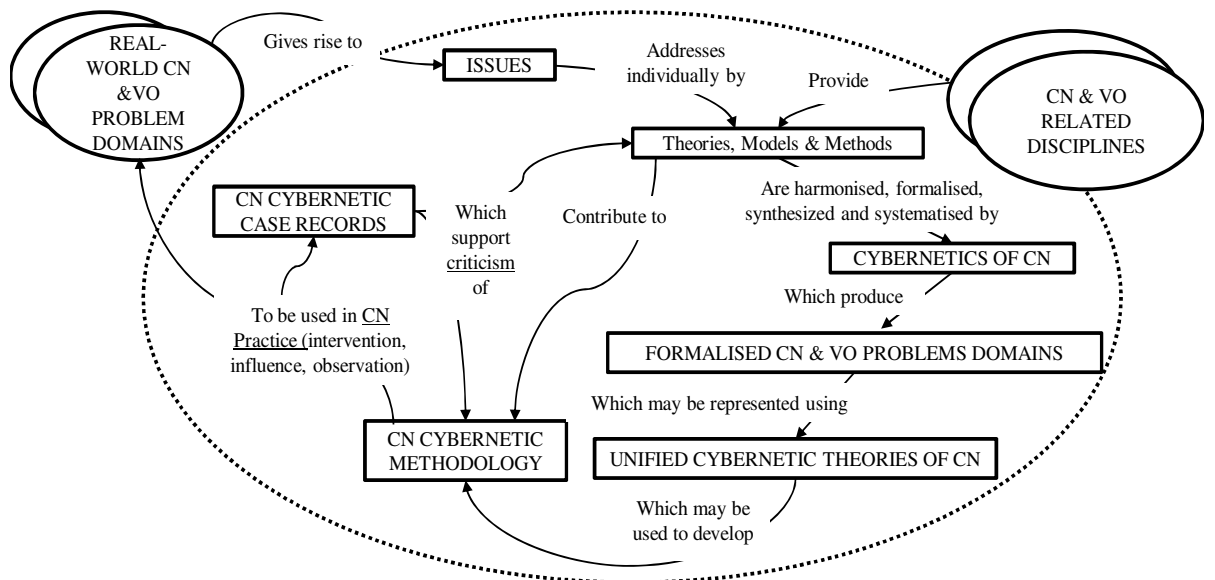

Fig. 1. Cybernetics of the CNs as a Developing Discipline - relationship between discipline development activities and results (based on [29] and [30])

\section{Towards a Reference Model of Self-designing Complex Collaborative Networked Enterprises}

This section's purpose is to create a shortlist of theories that addressed the complexity of large scale systems' management and control. The hallmark of these theories is that issues addressed by them re-appear in the $\mathrm{CN}$ research context, thus their relevance is established. The result of an extensive scan is summarised below.

Beer's Viable System Model (VSM) [31] views every system as consisting of three main interacting components: Management, Operation and Environment. Each entity in a $\mathrm{CN}$ business model has its management and operations. From every 
entity's point of view, the other entities are the environment. In VSM, every system needs a 'meta-system' (management of management) to be viable. From a VO's point of view, the other entities are not part of the environment but parts of the operations each with its own management, thus the VO may be considered a meta-system. There are communication channels ('variety attenuators and amplifiers') between these components to keep the operation in homeostasis [31,32,33]. The VSM model is to ensure that the Operation has enough 'variety' (relative to needs).

Beer's Recursive Systems Theorem [31] states that in the organisational structure "any viable system contains, and is contained in, a viable system." The theorem applied to CNs means a viable economy, industry, CNs, VOs, and partners all need to be considered as viable systems abiding by the axioms and principles of the VSM.

Ashby's Law of Requisite Variety [9] requires that to achieve dynamic stability under change, the variety of the Operation(s) should be equal to its relevant environment, and, the variety of management must be at least equal to that of Operations. A CN must maintain its requisite variety and communication channels to manage its complexity / maintain dynamic equilibrium with the environment[17]. These channels are the CN's self-perpetuating mechanisms.

Combining Ashby and Beer's theories. Consider the system and its environment as coupled entities. If one component is perturbed, the perturbation on the other is either amplified (positive feedback), or attenuated (negative feedback). The role of the negative feedback is to reverse the effect of perturbations and restore homeostasis (in which so-called 'critical variables' are stable), while positive feedback can create unstable states [34]. Variety amplifiers in CNs are change mechanisms for the network manager to control the change to structure or architecture of the network, to increase the Operation's variety. (NB variety amplifiers in enterprise architecture terminology are decision frameworks [19].) E.g., the network manager initiates a project to re-design the $\mathrm{CN}$ or to create a $\mathrm{VO}$ so as to create new variety.

CNs and VOs as live systems have a number of variables characterising essential survival properties. Ashby (1960) calls these 'essential variables' and defines survival as: "... a line of behaviour [that] takes no essential variable outside given limits" $[27,35]$. By definition, a line of behaviour outside these limits is on the non-viable system path and is fatal to the system. For a system to be adaptive, and viable, Ashby introduces two amplifier feedback loops $[27,35,36]$. The first makes small (e.g. parametric) corrections to the system, while the second changes the architecture of the system, and if the second loop does not respond to / anticipates changes in environment complexity, the system is on a non-viable path. Based on Ashby's theory of adaptation [27] and Umpleby [36] the first loop makes the system learn new behaviour for the present environment, and the second loop makes the system change, creating new behaviour for the future. As opposed to amplifiers, variety attenuators in CNs are simple feedback mechanisms (e.g. a network manager can see what the operations are doing at any one moment in time). Operational and tactical network managers do not instill change to the Operations: they control it by invoking established functions of resources and monitoring defined KPIs. Strategic network managers use control to change resources, structures, and network architecture. All of these are controls, but strategic controls include design and change mechanisms. 
Change in Complexity and Co-evolution in CNs. We observe that both a system and its environment evolve, potentially creating imbalance between the actual variety of our system of interest and the requisite variety to maintain homeostasis: systems that want to live long must co-evolve with their environment. Formally: the environment is an entity with a set of possible observable states; if two states require different response from the system then the system must differentiate them (thus they are different relevant states). The complexity of a system $\left(\mathrm{C}_{\mathrm{S}}\right)$ is defined to be the complexity of the model that the controller of the system maintains (appears to maintain) for managing the operations. The complexity of the system's environment $\left(\mathrm{C}_{\mathrm{E}}\right)$ is a relative notion and is defined to be the complexity of the model of the environment the controller of the system needs / appears to maintain in the system's homeostasis. E.g., in a $\mathrm{CN}$, network managers, brokers and VO management use models to understand and control the operations and to interact with the environment, and to identify the need to change (re-structure, re-design, re-architect).

The controllers of these entities in CNs use a model to understand and predict the environment. E.g. in a $\mathrm{CN}$, the network manager and broker must have a model of what network partners do (the operations) and a model to understand and predict the environment (market and customer requirements). Based on the theorem of the 'Good Regulator' [37], the 'environment model' must have predictive capability, so that the system can maintain a homeostatic trajectory in time (and space). This environment model would include models of external systems with which our system interacts, and a model of the rest of the environment.

This ever evolving nature of the CNs needs mechanisms to control organisational learning. In the context of CNs, we propose to use Conversation Theory (CT) [18], a cybernetic model of learning processes, as CT defines process-patterns of aware management and learning situations.

According to Aulin's Law of Requisite Hierarchy and Controllability an unstructured $\mathrm{CN}$ has the largest potential to create requisite variety, but the 'setup costs' can potentially outweigh the benefits [17]. An architectural solution is to create brokerages that create VOs. Adding a layer of virtual brokerages can eliminate excess complexity [17], which result confirms Aulin's law of requisite hierarchy “... the required number of control levels depends on the regulatory ability of the individual control loops: the weaker that ability, the more hierarchy is needed" [38]. Heylighen and Joslyn [38] propose that the best possible solution is to maximise the regulatory ability of a single layer and minimise the number of hierarchical layers of control. In other words, it is a desirable state for systems (e.g. CNs) to be able to design themselves out of the same subsystems which recursively have the same selfdesign properties. The current trend towards flattening organizational hierarchies can be described by maximising regulatory abilities of personnel and organizations, using better education and empowerment, management and technological support [38].

Heylighen's Law of Requisite Knowledge and Self-designing CNs. Selfdesigning CNs be understood through the law of requisite hierarchy, but also based on the law of the 'requisite knowledge'. The management of a $\mathrm{CN}$ must have the knowledge of what actions to take in which states of the change in the environment so as to be ready to respond to the change in variety of the environment $[38,39]$. 
Requisite knowledge refers to the designer's ability to discern the 'relevant sates' of the environment. If the designer is part of the system the designer's tacit knowledge enhances the designer's ability to discern among relevant states [40].

Extended Axiomatic Design for Lowering the Design Complexity of CNs. An important problem facing viability and evolvability of CNs and resulting VOs is complexity, because uncontrolled complexity can cause undesired $\mathrm{CN}$ - and VO characteristics [12]. Axiomatic Design (AD) Theory [21] explains reasons of emerging complexity, and offers a formal design theory with two design axioms that system designs must satisfy to minimise complexity. Using AD Theory and its extension [40] it is possible to measure the complexity of the CN and of its VOs operations (so-called 'System 1s' in VSM), and measure / reduce the complexity of VO creation ('Systems 4 and 5 in VSM) $[31,32,33]$ ).

\section{Conclusion}

The article defined 'Cybernetics of CNs' as a field of research intended to develop a unified cybernetic theory of CNs, addressing complexity management and control problems in CNs. The paper briefly discussed significant models that could provide ingredients for a synthesised reference model for self-designing complex CNs. Future work will focus on harmonising the terminologies used, and proposing axioms to formalise a unified theory. The synthesised reference model could serve as a 'terminological grounding' of the theory.

\section{References}

1. Camarinha-Matos, L.M., Afsarmanesh, H.: A roadmap for strategic research on virtual organizations. In: Processes and Foundations for Virtual Organizations. Kluwer Academic Publishers, Boston (2003)

2. Camarinha-Matos, L.M., Afsarmanesh, H. (eds.): Collaborative Networked Organizations. A Research Agenda for Emerging Business Models. Kluwer Academic Publishers, Boston (2004a)

3. Camarinha-Matos, L.M., Afsarmanesh, H.: The emerging discipline of collaborative networks. In: Virtual Enterprises and Collaborative Networks. Kluwer Academic Publishers, Boston (2004)

4. Camarinha-Matos, L.M., Afsarmanesh, H.: Collaborative networks: A new scientific discipline. Journal of Intelligent Manufacturing 16(4), 439-452 (2005a)

5. Camarinha-Matos, L.M., Afsarmanesh, H., Ollus, M.: ECOLEAD: A holistic approach to creation and management of dynamic virtual organizations. In: Collaborative Networks and their Breeding Environments, pp. 3-16. Springer (2005)

6. Camarinha-Matos, L., Afsarmanesh, H.: Towards a reference model for collaborative networked organizations. In: Information Technology for Balanced Manufacturing Systems, pp. 193-202 (2006)

7. Camarinha-Matos, L., Afsarmanesh, H.: Motivation for a theoretical foundation for collaborative networks. In: Collaborative Networks: Reference Modeling, pp. 5-14. Springer, Berlin (2008a) 
8. Camarinha-Matos, L.M., Afsarmanesh, H.: On reference models for collaborative networked organizations. Int. J. of Production Research 46(9), 2453-2469 (2008)

9. Ashby, W.R.: An introduction to cybernetics. Chapman \& Hall, London (1956)

10. Beer, S.: Decision and Control: The Meaning of Operational Research and Management Cybernetics. Wiley, New York (1966)

11. Bertalanffy, L.: General System Theory-Foundations and Developments. George Braziller, New York (1968)

12. Kandjani, H., Bernus, P.: Capability Maturity Model for Collaborative Networks Based on Extended Axiomatic Design Theory. In: Camarinha-Matos, L.M., Pereira-Klen, A., Afsarmanesh, H. (eds.) PRO-VE 2011. IFIP AICT, vol. 362, pp. 421-427. Springer, Heidelberg (2011a)

13. Kandjani, H., Bernus, P.: Evolution of the Enterprise Architecture Discipline: Towards a Unified Developing Theory of EA. In: Proc. ICEIS 2012, Warsaw (to appear, 2012a)

14. Wiener, N.: Cybernetics or Control and Communication in the Animal and the Machine. MIT Press, Cambridge (1948) (2nd rev. edn., 1961)

15. Beer, S.: Cybernetics and management. Wiley, New York (1959)

16. Boulding, K.E.: General systems theory-the skeleton of science. Management Science 2(3), 197-208 (1956)

17. Kandjani, H., Wen, L., Bernus, P.: Enterprise Architecture Cybernetics for Collaborative Networks: Reducing the Structural Complexity and Transaction Cost via Virtual Brokerage. In: Proc. INCOM 2012, Bucharest, Romania (to appear, 2012)

18. Pask, G.: Conversation, Cognition and Learning. Elsevier, Amsterdam (1975)

19. Doumeingts, G.: La Methode GRAI (PhD Thesis). U Bordeaux I, Bordeaux, France (1984)

20. Doumeingts, G.: GIM, Grai Integrated Methodology. In: Molina, A., Kusiak, A., Sanchez, J. (eds.) Handbook of Life Cycle Engineering, Models and Methodologies, pp. 227-288. Kluwer, Dordrecht (1998)

21. Suh, N.P.: The Principles of Design. Oxford University Press, New York (1990)

22. Gell-Mann, M.: Complex adaptive systems. in Complexity: Metaphors, models, and reality. In: Cowan, G.A., Pines, D., Meltzer, D. (eds.), pp. 17-45. Addison-Wesley, Reading (1994)

23. Holland, J.H.: Complex adaptive systems. Daedalus 121(1), 17-30 (1992)

24. Wooldridge, M.J.: An introduction to multiagent systems. Wiley, New York (2002)

25. Wooldridge, M.J., Jennings, N.R.: Intelligent Agents: Theory and Practice. Knowledge Engineering Review 10(2), 105-112 (1995)

26. Bødker, K., Kensing, F., Simonsen, J.: Participatory IT design: designing for business and workplace realities. The MIT Press (2004)

27. Ashby, W.R.: Design for a brain; the origin of adaptive behavior. Wiley, New York (1960)

28. Senge, P.M.: The Fifth Discipline: The Art and Practice of the Learning Organization. Doubleday, New York (1990)

29. Anderton, R.H., Checkland, P.B.: On learning our lessons. Internal Discussion Paper. Department of Systems, University of Lancaster. Lancaster, 2/77 (1977)

30. Checkland, P.: Systems Thinking, Systems Practice. Wiley \& Sons, Chichester (1996)

31. Beer, S.: The Heart of Enterprise: the Managerial Cybernetics of Organization. Wiley, New York (1979)

32. Beer, S.: Brain of the Firm, 2nd edn. Wiley, New York (1981)

33. Beer, S.: Diagnosing the system for organizations. Wiley, New York (1985)

34. Ashby, W.R.: Adaptiveness and equilibrium. British J. of Psychiatry 86(362), 478-483 (1940) 
35. Geoghegan, M.C., Pangaro, P.: Design for a self-regenerating organisation. Int. J. of General Systems 38(2), 155-173 (2009)

36. Umpleby, S.A.: Ross Ashby's general theory of adaptive systems. Int. J. of General Systems 38(2), 231-238 (2009)

37. Conant, R.C., Ashby, W.R.: Every Good Regulator of a System Must be a Model of That System. Int. J. of Systems Science 1(2), 89-97 (1970)

38. Heylighen, F., Joslyn, C.: Cybernetics and second order cybernetics. Encyclopedia of Physical Science \& Technology 4, 155-170 (2001)

39. Heylighen, F.: Principles of Systems and Cybernetics: an evolutionary perspective. Cybernetics and Systems 92, 3-10 (1992)

40. Kandjani, H., Bernus, P.: Engineering Self-Designing Enterprises as Complex Systems Using Extended Axiomatic Design Theory. In: IFAC Papers On Line, vol. 18(1), pp. 11943-11948. Elsevier, Amsterdam (2011) 